\title{
Fundamental Research on Cutting Performance of Water-Soluble Cutting Fluids Compared with Dry Hobbing*
}

\author{
Hironori MATSUOKA** ${ }^{*}$ Hajime $\mathrm{ONO}^{* * *}$ and Yoshihiro TSUDA**
}

\begin{abstract}
This paper deals with the comparison of water-soluble cutting fluids for hobbing with dry cutting in performance, in terms of flank wear, crater wear and finished surface roughness, using TiN and (Al,Ti)N coated high-speed steel cutting tools. The experiments were performed using a fly tool of the same geometry as that of one tooth of a hob on the milling machine. The results helped clarify the following points: (1) The flank wear and the crater wear obtained with the water-soluble cutting fluids are larger than those obtained with the dry cutting, when using both TiN and (Al,Ti)N coated tools at the cutting speed of $117 \mathrm{~m} / \mathrm{min}$, but in the case of the $(\mathrm{Al}, \mathrm{Ti}) \mathrm{N}$ coated tool at the high cutting speed of $159 \mathrm{~m} / \mathrm{min}$, they are small when using the fluids. (2) The finished surface roughness when using the fluids is almost larger than that obtained in dry cutting, irrespective of the change in the kinds of coating films and the cutting speeds. (3) At the high cutting speed of $159 \mathrm{~m} / \mathrm{min}$, the fluid containing the synthetic lubricating additive and the sulfuric EP additive is effective in the cutting performance compared with the dry cutting.
\end{abstract}

Key Words: Cutting, Gear, Dry Cutting, Water-Soluble Cutting Fluid, Emulsion, Tool Life, Hobbing, Fly Tool, Coated Tool, Crater Wear, Finished Surface Roughness

\section{Introduction}

In recent years, the environmental problems in regard to the use of cutting oils in machining, such as strains on workers during cutting and environmental pollution caused by disposal of waste cutting oils containing, for instance, chlorine compounds, which change into deleterious materials when they are destroyed by fire, have become a matter of great concern, rather than the improvement of cutting performance. In general cutting operations such as turning, drilling and milling, water-soluble cutting fluids and dry cutting without using the cutting fluids have been widely applied in the workshops.

In hobbing, the cutting oils (water-insoluble) have been exclusively used to improve tool wear and finished surface roughness. However, under the conditions of recent high speed and/or heavy cutting because of higher productivity, the use of the cutting oils involves serious problems, which are the deterioration of working environ-

\footnotetext{
* Received 6th September, 2004 (No. 04-4196)

** Department of Mechanical and Energy Systems Engineering, Oita University, 700 Dannoharu, Oita 870-1192, Japan. E-mail: hmatsuo@cc.oita-u.ac.jp

*** Yushiro Chemical Industry Co., Ltd., 1157-2 Yufune, Oyama-cho, Suntou-gun, Shizuoka 410-1305, Japan
}

ment caused by the generation of mist, smoke and offensive smell from the cutting oils, and the danger of catching fire. If it is possible to use the water-soluble cutting fluids for hobbing, not only the above problems will be solved, but also there is a little decrease in accuracy caused by the thermal expansion according to the excellent cooling ability. Moreover, being diluted with water, they have the advantages of economizing and saving resources.

The authors have investigated the comparison of cutting performance of a typical water-soluble cutting fluid with two kinds of water-insoluble cutting oils for gear cutting, by replacing the hobbing with the fly tool cutting on the milling machine. As a consequence, it has been clarified that the water-soluble cutting fluid tested was superior to the cutting oils, from the viewpoints of tool life and finished surface roughness ${ }^{(1)}$.

As the latest trend in hobbing, dry hobbing has become of major interest. In dry hobbing, however, there is much left to study whether it is possible to apply for all kinds of gear materials, hobbing methods and hobbing conditions or not. There also still remains many difficulties in the points of scratch marks on the surface of gear teeth and dimensional accuracy, as well as scattering and disposition of the cutting chips.

In this study, the cutting performance of water- 
soluble cutting fluids (emulsion types) compared with that of the dry cutting was investigated, in terms of the flank wear (tool life), the crater wear and the finished surface roughness, which lays the foundation of water-soluble cutting fluids for hobbing.

\section{Experimental Method and Conditions}

Tests were carried out by simulating the hobbing by fly tool cutting on the milling machine. In other words, testing the durability of a hob by actual hobbing is so complicated, because it is influenced by many factors, that after analyzing the size of cutting chips produced by the tooth of the hob carrying the greatest load, a fly tool of the same shape as a single hob tooth was made to perform cutting identical to this tooth on the milling machine. For the correspondency between hobbing and fly tool cutting, one of the authors has recognized that the results, e.g., the flank wear and the surface roughness, obtained by the fundamental tests using a fly tool agree with those obtained by hobbing ${ }^{(2)}$. Therefore, the experimental results using the fly tool cutting seem adequate for adaptation to hobbing on the hobbing machine.

The dimensions of the gear and the hob, which became the objects in the experiments, are listed in Table 1. The experimental conditions for the milling machine are listed in Table 2. The fly tool material used in these tests is formed from high-speed steel equivalent to JIS SKH55, which was coated with TiN or (Al,Ti)N films by the arc ion plating method [the terms are abbreviated as TiN coated tool and (Al,Ti)N coated tool]. The cutting tests were conducted without coating on the rake face of the fly tools,

Table 1 Dimensions of the gear and hob

\begin{tabular}{|c|c|c|c|}
\hline \multicolumn{2}{|c|}{ Gear } & \multicolumn{2}{|c|}{ Hob } \\
\hline Module & 3 & Module & 3 \\
\hline \multirow{2}{*}{ Pressure angle } & \multirow{2}{*}{$20^{\circ}$} & Pressure angle & $20^{\circ}$ \\
\hline & & Lead angle & $4^{\circ} 35^{\prime} 18^{\prime \prime}$ \\
\hline Number of teeth & 42 & \multirow{2}{*}{ Form } & \multirow{2}{*}{$\begin{array}{l}\text { 3-thread, } \\
\text { Right hand }\end{array}$} \\
\hline Helix angle & $0^{\circ}$ & & \\
\hline Pitch diameter & $126 \mathrm{~mm}$ & \multicolumn{2}{|c|}{$\phi 118 \times 125 \times \phi 40$} \\
\hline \multirow{2}{*}{ Face width } & \multirow{2}{*}{$40 \mathrm{~mm}$} & Rake angle & $0^{\circ}$ \\
\hline & & Relief angle & $12^{\circ}$ \\
\hline Cutting depth & $6.75 \mathrm{~mm}$ & Number of gash & 12 \\
\hline \multicolumn{2}{|c|}{ Tooth profile Full depth tooth } & Gash & Straight \\
\hline
\end{tabular}

Table 2 The same conditions as in the case of hobbing by fly tool cutting on milling machine

\begin{tabular}{c|c|c|c}
\hline \multicolumn{2}{c|}{ Hobbing } & \multicolumn{2}{c}{ Fly tool cutting on milling machine } \\
\hline \multicolumn{2}{c|}{ 3-thread hob } & Feed of table & $0.99 \mathrm{~mm} / \mathrm{rev}$ \\
\hline Feed of hob & $3.0 \mathrm{~mm} / \mathrm{rev}$ & Depth of cut & $3.25 \mathrm{~mm}$ \\
\hline $\begin{array}{c}\text { Length of } \\
\text { maximum chip }\end{array}$ & $23.57 \mathrm{~mm}$ & \multicolumn{2}{|c}{ For cutting corresponding to the gear } \\
\cline { 3 - 4 } & $\begin{array}{c}\text { Total number of revolutions } \\
\text { (The sum of the approach } \\
\text { distance and face width ) }\end{array}$ & 315 \\
\cline { 3 - 5 } $\begin{array}{c}\text { Thickness of } \\
\text { maximum chip }\end{array}$ & $0.27 \mathrm{~mm}$ & Length of groove to be cut & $0.31 \mathrm{~m}$ \\
\hline
\end{tabular}

Note: The turning radius of the tip of fly tool is $85 \mathrm{~mm}$. because the hobs are usually used without coating on the rake face by regrinding in many cases in the workshops. The thickness of both coating films is about $5 \mu \mathrm{m}$. The work material is chromium molybdenum steel of SCM415 (HB143), which has the dimensions of $500 \mathrm{~mm}$ length, $100 \mathrm{~mm}$ width and $100 \mathrm{~mm}$ thickness. The cutting speeds are $117 \mathrm{~m} / \mathrm{min}$ and $159 \mathrm{~m} / \mathrm{min}$.

Figure 1 shows the wear which took place at the tip of the tool. The center wear width and top corner part wear width on the top cutting edge, and the corner wear width which occurred at the boundary region between the roundish portion on the top cutting edge and the side cutting edge were measured using a microscope. Moreover, photographs of these flank wear and crater wear examples were obtained by a camera. The cutting length of groove of $20 \mathrm{~m}$ in fly tool cutting on the milling machine, at a cutting speed of $117 \mathrm{~m} / \mathrm{min}$ in the present experiments, corresponds to the hobbing of 64.5 gears on the hobbing machine. Since there are some cases that it is impossible to cut the groove length of $20 \mathrm{~m}$ at a cutting speed of $159 \mathrm{~m} / \mathrm{min}$, because of rapid increase in the flank wear in the initial stage of cut, the cutting groove length, at which the width of maximum flank wear among the center wear, the top corner part wear and the corner wear reached $0.3 \mathrm{~mm}$, was adopted as the tool life.

25 points for the depth and the profile of crater wear were measured at intervals of $0.1 \mathrm{~mm}$ as shown in Fig. 2. The finished surface roughness was measured on the bottom of the cutting groove in the cutting direction. The crater wear and the finished surface roughness Ry were measured with the surface measuring instrument. The

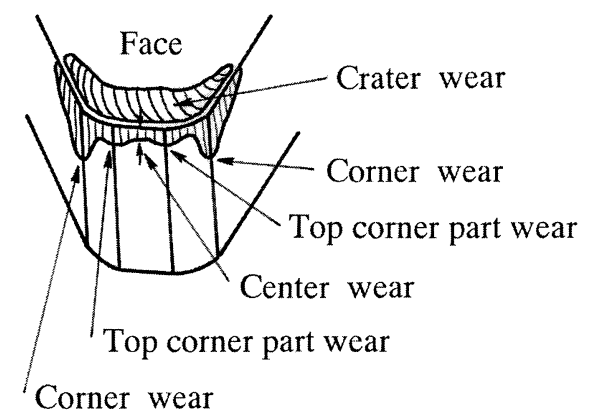

Fig. 1 Wear at cutting edge

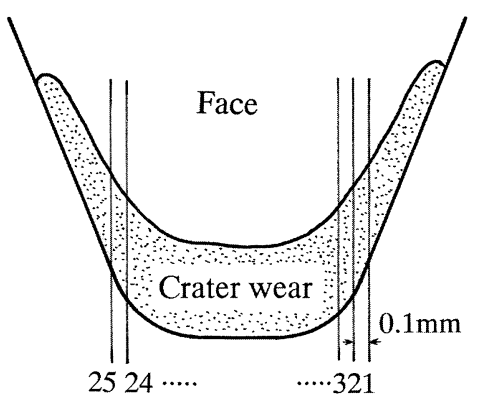

Fig. 2 Measurement position of crater wear 
Table 3 Properties of water-soluble cutting fluids tested

\begin{tabular}{|c|c|c|c|c|c|}
\hline \multicolumn{2}{|l|}{ Item } & Fluid A & Fluid B & Fluid $\mathrm{C}$ & Fluid D \\
\hline \multirow{2}{*}{ Appearance } & Original & $\begin{array}{l}\text { Dark green } \\
\text { liquid }\end{array}$ & $\begin{array}{l}\text { Yellow } \\
\text { liquid }\end{array}$ & $\begin{array}{l}\text { Light yellow } \\
\text { liquid }\end{array}$ & $\begin{array}{l}\text { Dark green } \\
\text { liquid }\end{array}$ \\
\hline & $\times 30$ & $\begin{array}{l}\text { Light green } \\
\text { emulsion }\end{array}$ & $\begin{array}{l}\text { White } \\
\text { emulsion }\end{array}$ & $\begin{array}{l}\text { White } \\
\text { emulsion }\end{array}$ & $\begin{array}{l}\text { Light green } \\
\text { emulsion }\end{array}$ \\
\hline $\begin{array}{l}\text { Specific gravity } \\
\left(15^{\circ} \mathrm{C}, \mathrm{g} / \mathrm{cm}^{3}\right)\end{array}$ & Original & 1.012 & 0.945 & 0.946 & 0.950 \\
\hline $\mathrm{pH}$ & $\times 30$ & 9.3 & 9.4 & 9.8 & 9.6 \\
\hline $\begin{array}{l}\text { Surface tension } \\
(\mathrm{mN} / \mathrm{m})\end{array}$ & $\times 30$ & 32 & 32 & 32 & 32 \\
\hline $\begin{array}{l}\text { Synthetic lubricating } \\
\text { additive }\end{array}$ & Original & 一 & (0) & 0 & 0 \\
\hline Mineral oil & Original & - & - & (2) & (2) \\
\hline Sulfuric EP additive & Original & () & - & - & $\triangle$ \\
\hline Surface active agent & Original & $\triangle$ & $\triangle$ & $\triangle$ & $\Delta$ \\
\hline
\end{tabular}

milling machine used in the tests is the 2MF Model (Universal type) manufactured by Hitachi Seiki Co., Ltd.

The properties of water-soluble cutting fluids (the terms will hereinafter be abbreviated "fluids") used in the tests, which are available in the market, are shown in Table 3. Fluid A; a fluid containing sulfurous EP additive, Fluid B; a fluid containing synthetic lubricating additive, Fluid C; a fluid in which approximately a half amount of the synthetic lubricating additive was replaced by that of mineral oil, and Fluid D; a fluid in which a small quantity of sulfurous EP additive was added to the Fluid C. Moreover, the synthetic lubricating additives used for the Fluids B, C and D are organic acid esters, polyalkyleneglycols and so on, which are generally used as a base oil of synthetic lubricating fluids. The fluid is diluted with water to 30 times, and it was sufficiently flooded from the rake face side at a constant flow rate of $2.4 \mathrm{~L} / \mathrm{min}$.

\section{Experimental Results and Discussions}

In order to confirm the reproducibility of tool wear and surface roughness in this study, tests were performed two times under several conditions. The reproducibility of these tests was rather good. This paper also deals with the comparison of the dry cutting and the fluids in the cutting performance, so the mechanisms of the actions of the fluids tested will be reported in another paper.

\subsection{Flank wear (Tool life)}

Figure 3 shows the comparison of the width of flank wear. These data are the results after cutting length of groove of $20 \mathrm{~m}$ at the cutting speed of $117 \mathrm{~m} / \mathrm{min}$. In the case of the TiN coated tool, the width of maximum wear, which is the greatest of the three, namely, center wear, top corner part wear and corner wear, obtained with the fluids are approximately two times as large as that obtained in the dry cutting. When the fluids were used, the corner wear are larger than the center wear and the top corner part wear on the top cutting edge. On the other hand, the width of each flank wear in the dry cutting showed almost the same values. Even in the case of the $(\mathrm{Al}, \mathrm{Ti}) \mathrm{N}$ coated tool, the width of maximum wear obtained when using the fluids are from two times to three times larger compared

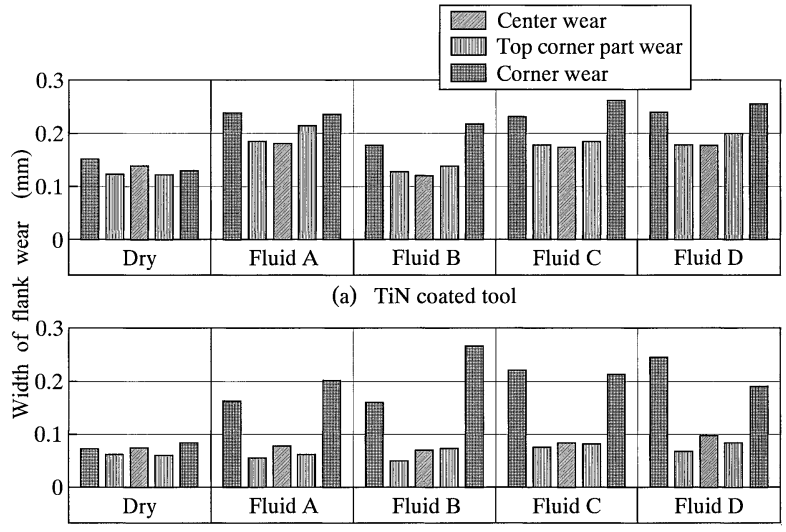

(b) $(\mathrm{Al}, \mathrm{Ti}) \mathrm{N}$ coated tool

Fig. 3 Comparison of the flank wear in dry cutting and when using the water-soluble cutting fluids (cutting speed of $117 \mathrm{~m} / \mathrm{min}$, cutting length of groove of $20 \mathrm{~m}$ )

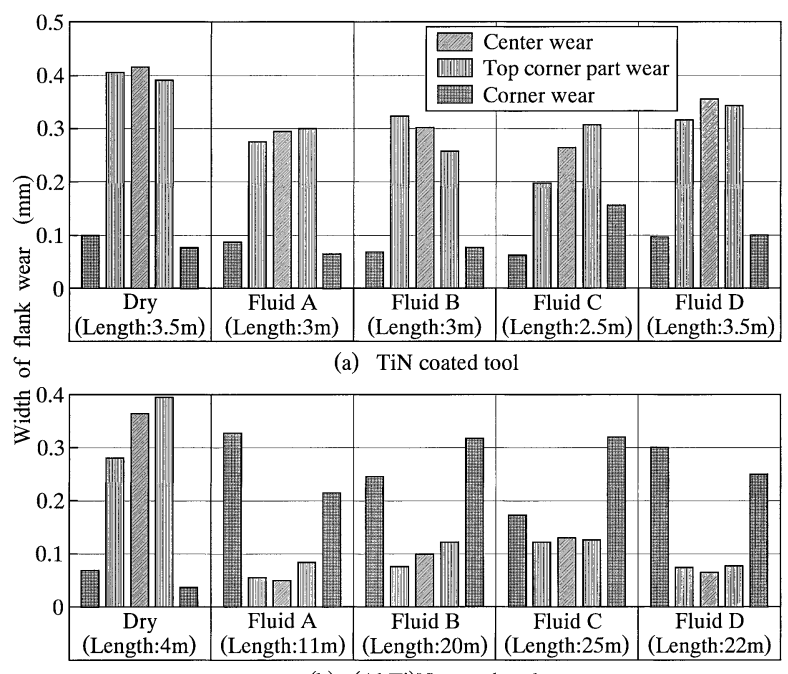

(b) $(\mathrm{Al}, \mathrm{Ti}) \mathrm{N}$ coated tool

Fig. 4 Comparison of the flank wear in dry cutting and when using the water-soluble cutting fluids (cutting speed of $159 \mathrm{~m} / \mathrm{min}$ )

with that obtained in the dry cutting. Meanwhile, when the fluids were used, although the center wear and the top corner part wear show nearly the same values as those in the dry cutting, the corner wear are large.

Figure 4 shows the comparison of the width of flank wear, in which the maximum one reached beyond the tool life criterion of $0.3 \mathrm{~mm}$ at the cutting speed of $159 \mathrm{~m} / \mathrm{min}$. With the TiN coated tool, both in the dry cutting and when using the fluids, the center wear and the top corner part wear are larger than the corner wear, which dominated the tool life, and these phenomena occur in the early stage of $2.5-3.5 \mathrm{~m}$ in cutting groove length. On the other hand, though the similar wear tendency to that shown above was seen in the dry cutting with the $(\mathrm{Al}, \mathrm{Ti}) \mathrm{N}$ coated tool, the center wear and the top corner part wear are small in spite of a long cutting groove length, when using the fluids.

Since it is difficult to determine the difference in the 


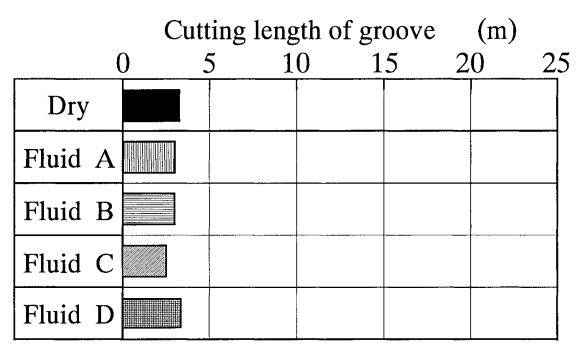

(a) TiN coated tool

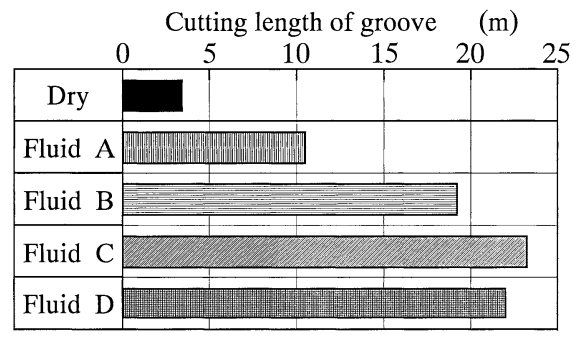

(b) $(\mathrm{Al}, \mathrm{Ti}) \mathrm{N}$ coated tool

Fig. 5 Comparison of the tool life in dry cutting and when using the water-soluble cutting fluids (cutting speed of $159 \mathrm{~m} / \mathrm{min}$, tool life criterion: maximum flank wear $0.3 \mathrm{~mm})$

width of flank wear from the results shown in Fig. 4, because the cutting groove length which reached the tool life under each condition is different, the comparison of the tool lives were performed as shown in Fig. 5. The tool life criterion is the maximum flank wear of $0.3 \mathrm{~mm}$. With the TiN coated tool, the tool lives obtained with the fluids are almost the same as that in the dry cutting, which are very short because the cutting groove length is about $3 \mathrm{~m}$ (this corresponds to the hobbing of 10 gears). On the contrary, in the case of the $(\mathrm{Al}, \mathrm{Ti}) \mathrm{N}$ coated tool, the tool lives with the fluids, especially with Fluids C and D, showed the groove length of above $20 \mathrm{~m}$ and increased seven times and more than that in the dry cutting, which is approximately a short cutting length of groove of $3 \mathrm{~m}$.

From the above results, the dry cutting is effective at the cutting speed of $117 \mathrm{~m} / \mathrm{min}$, which may be a limit of the dry cutting in this work, but at the high speed of $159 \mathrm{~m} / \mathrm{min}$, the water-soluble cutting fluids tested improve the tool life dramatically comparing with the dry cutting. Especially the fluid containing the synthetic lubricating additive and the sulfuric EP additive is effective for hobbing. Moreover, it was clarified that there is a difference in the width of flank wear between the TiN and (Al,Ti)N coated tools, and between in the dry cutting and when using the fluids. We will discuss the reasons.

\subsection{Progress curves of flank wear}

Figure 6 shows the progress curves of the maximum flank wear in the dry cutting, and when using Fluids $\mathrm{C}$ and $\mathrm{D}$ as the representations in the fluids. The cutting speed is $117 \mathrm{~m} / \mathrm{min}$. In the case of the dry cutting with the TiN

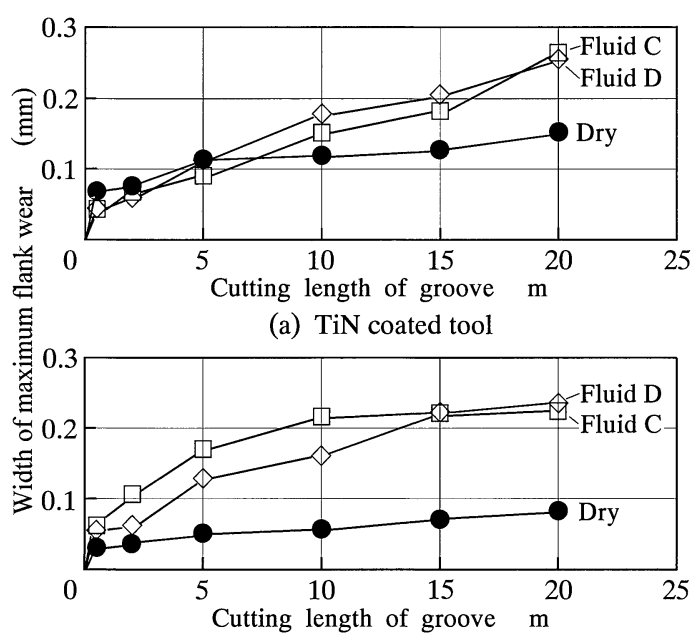

(b) $(\mathrm{Al}, \mathrm{Ti}) \mathrm{N}$ coated tool

Fig. 6 Progress curves of the maximum flank wear (cutting speed of $117 \mathrm{~m} / \mathrm{min}$ )

coated tool, though the flank wear increases in the same rate as that with Fluids $\mathrm{C}$ and D until the cutting groove length of $5 \mathrm{~m}$, and after that, it increases gradually. On the other hand, when using Fluids C and D, the flank wear shows much increasing rate compared with the dry cutting and increases linearly until the end of cutting. With the $(\mathrm{Al}, \mathrm{Ti}) \mathrm{N}$ coated tool, the flank wear in the dry cutting hardly increases until the cutting length groove of $20 \mathrm{~m}$, at which the maximum wear showed only $0.08 \mathrm{~mm}$ in width. In comparison with this result, in the cases of Fluids $C$ and $\mathrm{D}$, the flank wear increases faster than that obtained in the dry cutting until the cutting groove of $10 \mathrm{~m}$ in length, and after that, it increases gradually. The progress curves obtained with Fluids A and B also show the similar tendency to those obtained with Fluids $\mathrm{C}$ and D.

The progress curves obtained at the cutting speed of $159 \mathrm{~m} / \mathrm{min}$ are given in Fig. 7. In the case of the TiN coated tool, the maximum flank wear increases rapidly until the groove length of $3 \mathrm{~m}$ or $4 \mathrm{~m}$, both in the dry cutting and with Fluids C and D, therefore, there is recognized no significant difference between the dry cutting and when using the fluids. When using the $(\mathrm{Al}, \mathrm{Ti}) \mathrm{N}$ coated tool in the dry cutting, the maximum flank wear increases rapidly until the cutting groove length of $4 \mathrm{~m}$ as same as in the case of the TiN coated tool. However, although the flank wear with Fluids C and D shows almost the same value as that obtained in the dry cutting until the groove length of $2 \mathrm{~m}$, after that, the rate of increase in the flank wear is small in comparison with that obtained with the dry cutting. When using Fluids $\mathrm{A}$ and $\mathrm{B}$, the trend of progress curves are nearly the same as those with Fluids C and D.

\subsection{Flank wear pattern}

Figure 8 shows the maximum flank wear in the dry cutting and when using Fluid D as a typical example, after cutting a groove length of $20 \mathrm{~m}$ at the cutting speed 


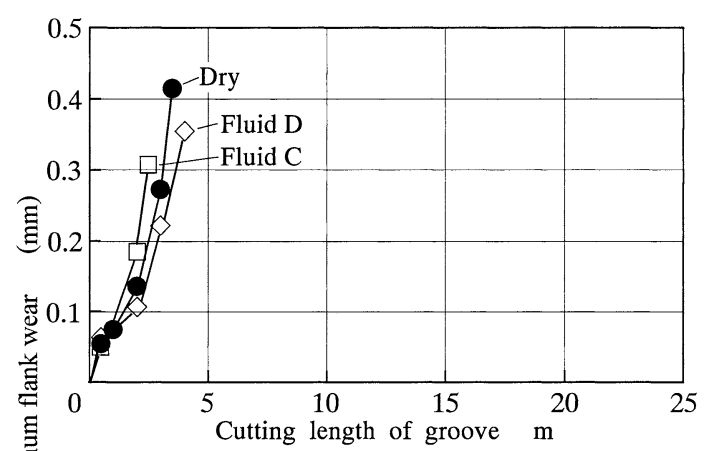

(a) TiN coated tool

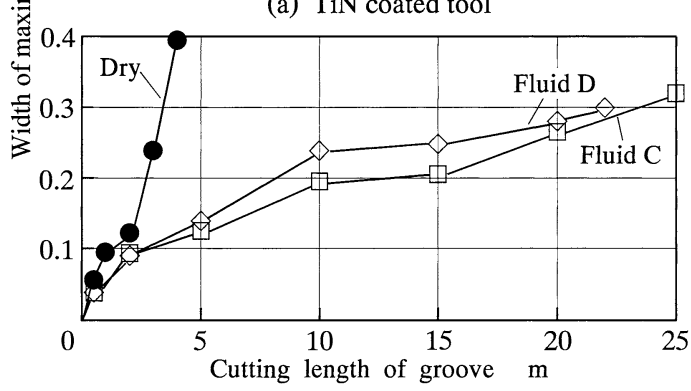

(b) $(\mathrm{Al}, \mathrm{Ti}) \mathrm{N}$ coated tool

Fig. 7 Progress curves of the maximum flank wear (cutting speed of $159 \mathrm{~m} / \mathrm{min}$ )

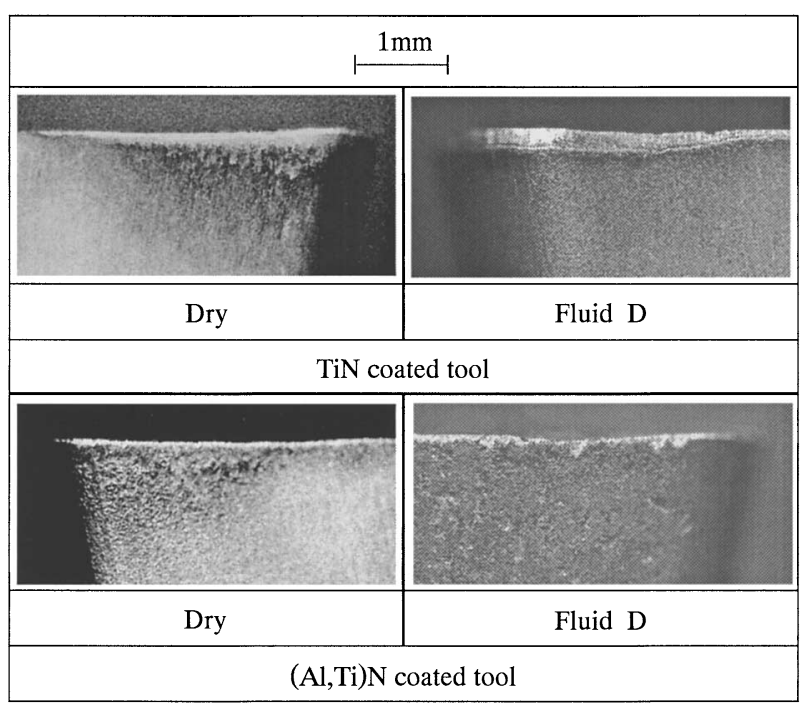

Fig. 8 Conditions of the maximum flank wear (cutting speed of $117 \mathrm{~m} / \mathrm{min}$, cutting length of groove of $20 \mathrm{~m}$ )

of $117 \mathrm{~m} / \mathrm{min}$. In the case of TiN coated tool in the dry cutting, the flank wear is almost uniform without the occurrence of chipping, which is thought to be an abrasive wear pattern. The flank wear obtained with Fluid D is also seemed to be the same wear pattern as in the dry cutting, but it is recognized that the boundary between the wear area and the coating film of the flank face appears clearly. With the $(\mathrm{Al}, \mathrm{Ti}) \mathrm{N}$ coated tool, it is considered that the wear pattern in the dry cutting is the abrasive wear without chipping. When using the Fluid D, however, some saw-toothed wear occur on the side cutting edge, there-

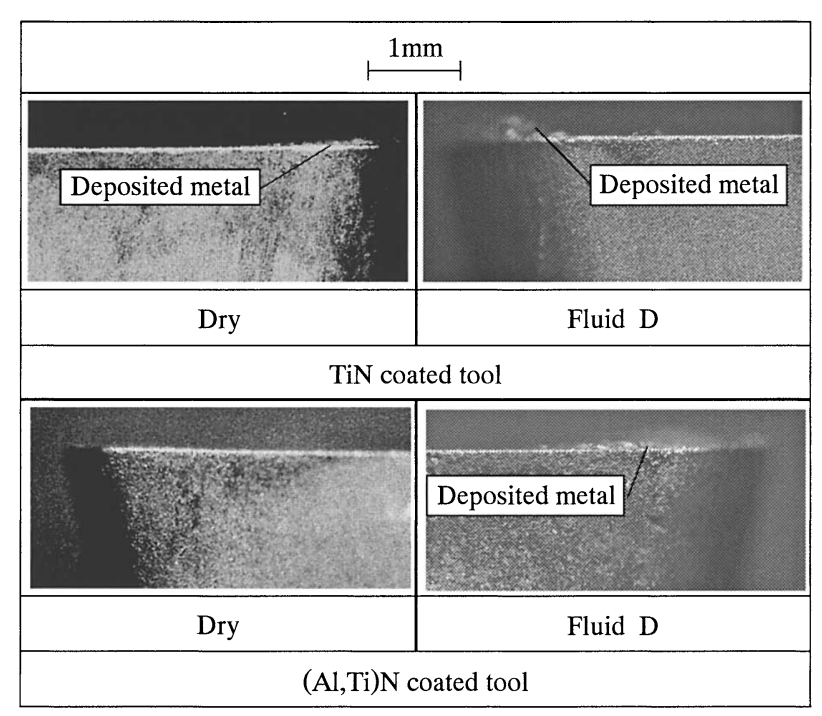

Fig. 9 Conditions of the flank at the beginning of cut (cutting speed of $117 \mathrm{~m} / \mathrm{min}$, cutting length of groove of $0.5 \mathrm{~m}$ )

fore, the largest wear of them decided the tool life.

In order to investigate these wear mechanisms, the conditions of the cutting edge at the beginning of cut (after cutting length of groove of $0.5 \mathrm{~m}$ ) were observed in the dry cutting and when using the Fluid D, as shown in Fig. 9. Both with the TiN and (Al,Ti)N coated tools in the dry cutting, since the adhesion of the deposited metal was hardly recognized on the cutting edge, but a little deposited metal was seen on the rake face, it seems that the flank wear pattern is, what is called, a mechanical abrasion ${ }^{(3)}$ caused by hard particles, such as impurities and metal carbides contained in the work material. On the contrary, in the case of TiN coated tool when using the fluid, there can be seen much adhesion of the deposited metal on the cutting edge and the rake face. Hence, the flank wear pattern is thought to be a three-body abrasive wear ${ }^{(4)}$ well known in the fields of tribology, which occurs according to the rubbing by the hard particles of the deposited metal flowing into the contact areas between the tool flank and the work material, added to the action of the above impurities and metal carbides contained in the work material. Therefore, it is assumed that the flank wear when using the fluids is larger than that in the dry cutting.

With the $(\mathrm{Al}, \mathrm{Ti}) \mathrm{N}$ coated tool when using the fluid, on the other hand, it is considered that the flank wear pattern is a transfer typed wear ${ }^{(3)}$, which occurred due to the localized seizure of the coating film and the substrate caused by the tearing off of the deposited metal from the cutting edge, because the adhesion of the deposited metal was observed along the cutting edge at the beginning of cut. Moreover, since these localized large wear have a tendency to occur on the side cutting edge, not on the top cutting edge takes place, this seems a reason why the corner wear are lager than the top corner wear and the center 


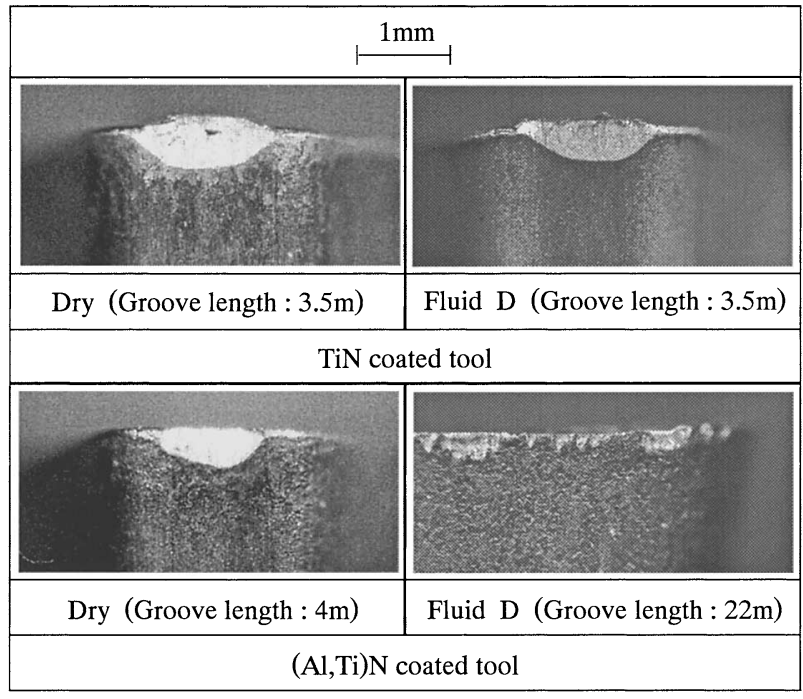

Fig. 10 Conditions of the maximum flank wear (cutting speed of $159 \mathrm{~m} / \mathrm{min}$ )

wear (see Fig. 3 (b)).

Figure 10 shows the photographs of the maximum flank wear which reached $0.3 \mathrm{~mm}$ in width at the cutting speed of $159 \mathrm{~m} / \mathrm{min}$. Both in the dry cutting and when using the Fluid D in the case of TiN coated tool, a large flank wear takes place at the center of the top cutting edge, and much deposited metal adhere on the rake face, which have be recognized from the initial stage of cut. Furthermore, the deposited metal flows into the area of the flank wear, which adheres on it. Thus, from the above results, it is supposed that the large flank wear is the composite wear pattern; one is the three-body adhesive wear, the other is the transfer typed wear. Meanwhile, the same wear pattern as the TiN coated tool was obtained in the dry cutting with (Al,Ti) N coated tool.

The reason why the center wear and the top corner part wear are large is seemed that the cutting chip thickness around the center of the top cutting edge is thickest at the cutting edge ${ }^{(5)}$, which loads the cutting edge heavily at the high cutting speed, so the TiN and (Al,Ti)N coating films could not overcome the running load of the cutting chips.

However, in the case of use of the fluid with the $(\mathrm{Al}, \mathrm{Ti}) \mathrm{N}$ coated tool, the large flank wear at the center of the top cutting edge does not appear, and some sawtoothed wear, which are considered to be caused by the seizure of the coating film and/or the occurrence of the chipping according to the tearing off of the deposited metal from the cutting edge, are seen on the side cutting edge, in which the localized largest wear decided the tool life. Thus, it is assumed that the fluids with the $(\mathrm{Al}, \mathrm{Ti}) \mathrm{N}$ coated tool prevent the abnormal wear caused at the center of the top cutting edge.

From the above results, it is thought that the de-

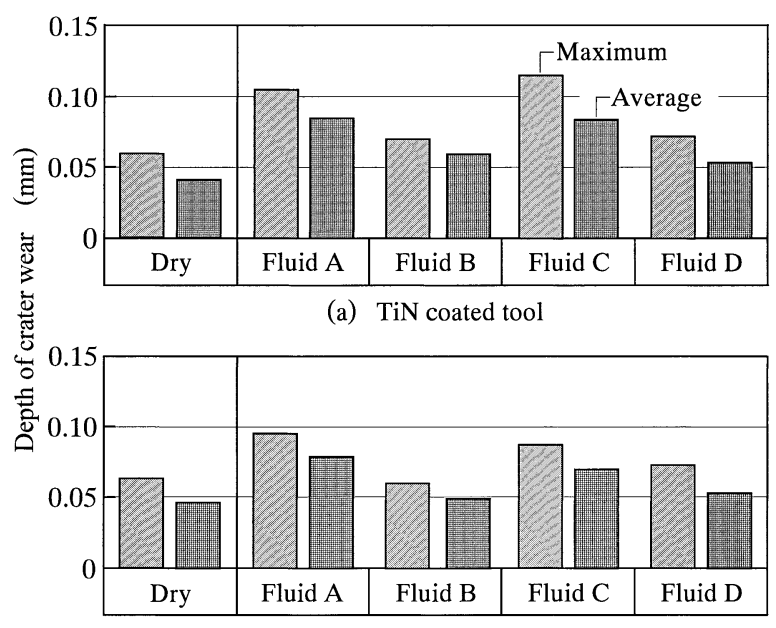

(b) $(\mathrm{Al}, \mathrm{Ti}) \mathrm{N}$ coated tool

Fig. 11 Comparison of the crater wear in dry cutting and when using the water-soluble cutting fluids (cutting speed of $117 \mathrm{~m} / \mathrm{min}$, cutting length of groove of $20 \mathrm{~m}$ )

posited metal takes part in the occurrence of the flank wear in the dry cutting and when using the fluids. The reason why the flank wear obtained when using the fluids is larger than that in the dry cutting at the cutting speed of $117 \mathrm{~m} / \mathrm{min}$ is assumed to depend on the occurrence of much deposited metal. That is, the cutting temperature decreases according to the use of the fluids compared with the dry cutting ${ }^{(6)}$, at which a relatively easy occurrence of much deposited metal was brought about. The reason why the tool life increases, in the case of use of the fluids with the $(\mathrm{Al}, \mathrm{Ti}) \mathrm{N}$ coated tool at the high cutting speed of $159 \mathrm{~m} / \mathrm{min}$, is considered that not only the rich cooling ability of the fluids, but also the high reactivity and the high absorbency of additives in the fluids, such as sulfur and ester act to the flank wear effectively.

\subsection{Crater wear}

It seems that the difference in lubricating effect and cooling ability on the rake face, between in the dry cutting and when using the fluid, would considerably appear in comparison with those on the flank face, due to the high temperature and high pressure according to the direct contact between the rake face and the cutting chips. In addition, it has been reported that the corner wear on the flank face is caused by a collapse of the edge of the crater wear ${ }^{(7)}$, therefore, the crater wear is also an important factor to influence on the tool life.

Figure 11 shows the depth of crater wear after a cutting groove length of $20 \mathrm{~m}$ in the dry cutting and when using the fluids at the cutting speed of $117 \mathrm{~m} / \mathrm{min}$. The maximum value of the crater wear (the greatest in 25 measurement points for the depth of crater wear, see Fig. 2) and the mean value of the crater wear (the average of those 25 points) are given. Both in the cases of the TiN and $(\mathrm{Al}, \mathrm{Ti}) \mathrm{N}$ coated tools, although there are some fluids which show almost the same depth of crater wear as in 


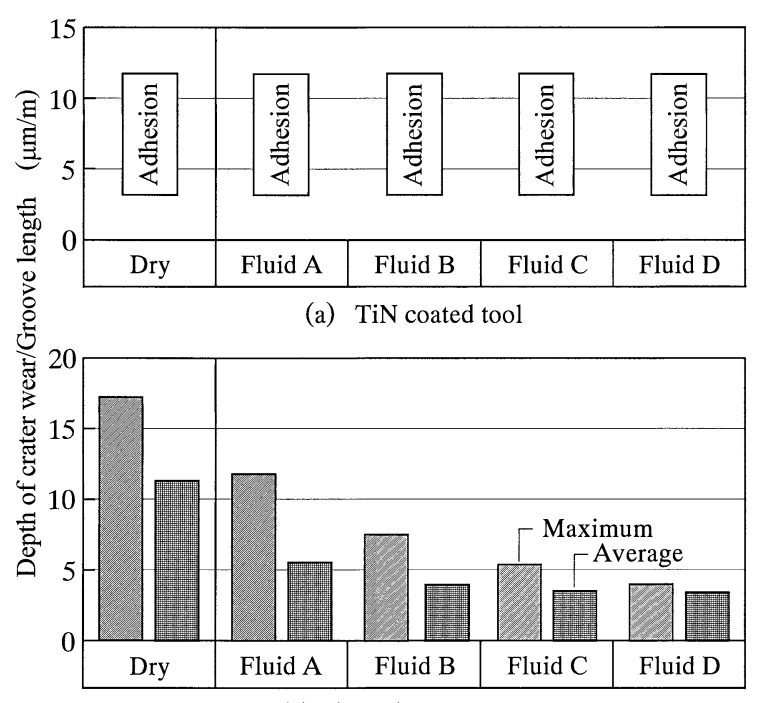

(b) $(\mathrm{Al}, \mathrm{Ti}) \mathrm{N}$ coated tool

Fig. 12 Comparison of the crater wear in dry cutting and when using the water-soluble cutting fluids (cutting speed of $159 \mathrm{~m} / \mathrm{min}$, per cutting length of groove of $1 \mathrm{~m}$ )

the dry cutting, they are large when using the fluids on the whole.

The results obtained at the cutting speed of $159 \mathrm{~m} / \mathrm{min}$ are shown in Fig. 12. The depth of crater wear per $1 \mathrm{~m}$, which was obtained with dividing the crater wear depth by the cutting groove length, was evaluated, because there are differences in the cutting groove length obtained with the dry cutting and the fluids. In the case of the dry cutting and when using the fluids with the TiN coated tool, as the rake face was covered with the deposited metal, it was difficult to measure the real depth of crater wear. With the $(\mathrm{Al}, \mathrm{Ti}) \mathrm{N}$ coated tool, the crater wear with the fluids are smaller than that in the dry cutting, especially, in the case of use of the Fluid D, the smallest crater wear was obtained in the fluids tested.

The conditions of the rake face, in the dry cutting and when using the Fluid D as an example after cutting a groove of $20 \mathrm{~m}$ in length at the cutting speed of $117 \mathrm{~m} / \mathrm{min}$, were observed, as shown in Fig. 13. In the dry cutting with the TiN coated tool, a mark by the rubbing of the cutting chips (this is abbreviated to "rubbing mark") is recognized around the tip of the cutting edge, and a mark, just like a seizure of substrate (this is abbreviated to "seizure mark"), which is considered to be caused by the tearing off of the deposited metal when the cutting chips are discharged, is seen on the right and left sides of the contact surface with the cutting chips. The crater wear condition when using the Fluid D is similar to that in the dry cutting, but the region of the seizure mark is small. With the $(\mathrm{Al}, \mathrm{Ti}) \mathrm{N}$ coated tool, the similar crater wear conditions to the TiN coated tool were also recognized.

Here, the seizure mark occurred on the both sides of the contact surface, in other words, in the areas near the

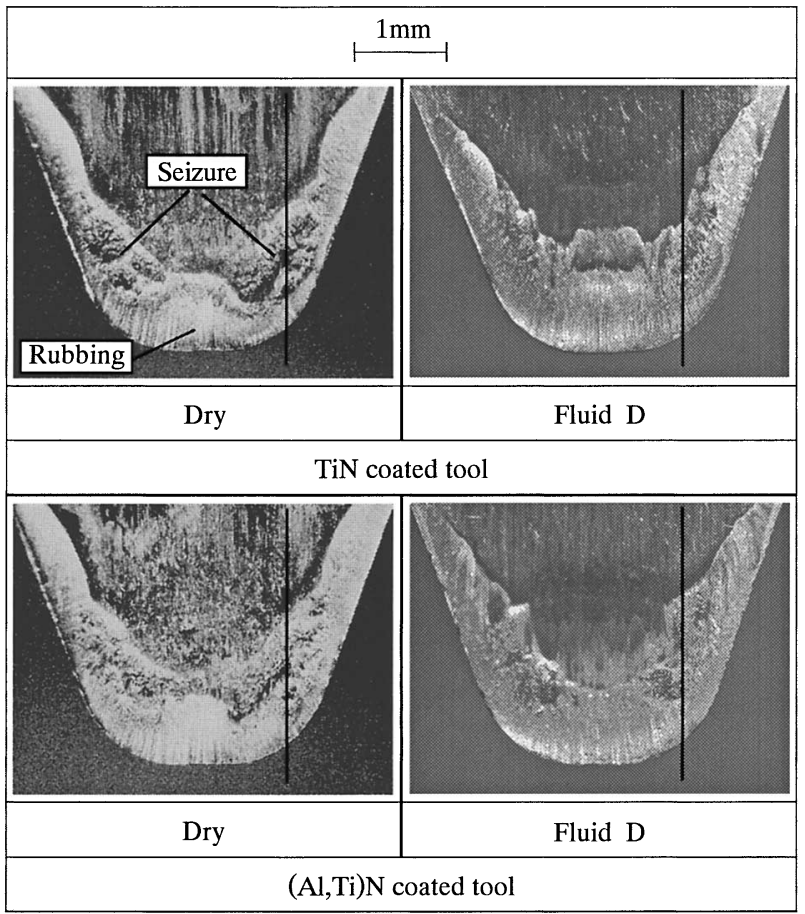

Fig. 13 Conditions of the rake face (cutting speed of $117 \mathrm{~m} / \mathrm{min}$, cutting length of groove of $20 \mathrm{~m}$ )

boundary between the nose roundish portion and the side cutting edge. The reason for this may be assumed as follows. A hob tooth has three cutting edges, the top cutting edge, the nose roundish portion and the side cutting edge, and since the cutting chips having different outflow directions on the rake face, which were cut by these cutting edges, collide one another, the interference of the cutting chips ${ }^{(8),(9)}$ is considered to occur in the area. Therefore, the occurrence of seizure mark is supposed in order that the place especially becomes high temperature and high pressure.

Figure 14 shows the profiles of the crater wear at the positions of a perpendicular line drawn on the rake face given in Fig. 13. In the case of the dry cutting with the TiN and (Al,Ti)N coated tools, the adhesion of the deposited metal is recognized at the center of the crater wear. On the contrary, when using the fluid, no deposited metal on the crater wear is seen. From these results, the reason why the crater wear is small in the dry cutting is considered that the deposited metal prevents the progress of the crater wear. In Fig. 9, though the adhesion of the deposited metal at the cutting edge was hardly recognized both with TiN and (Al,Ti)N coated tools in the dry cutting, it is seen on the rake face in the initial stage of cut, as shown in Fig. 15. From the results given in Fig. 14, it is assumed that the deposited metal occurred in the dry cutting adheres strongly on the rake face, but the adhesion of the deposited metal occurred when using the fluids is weak.

Hiroi and Nakayama have reported that the tool life 


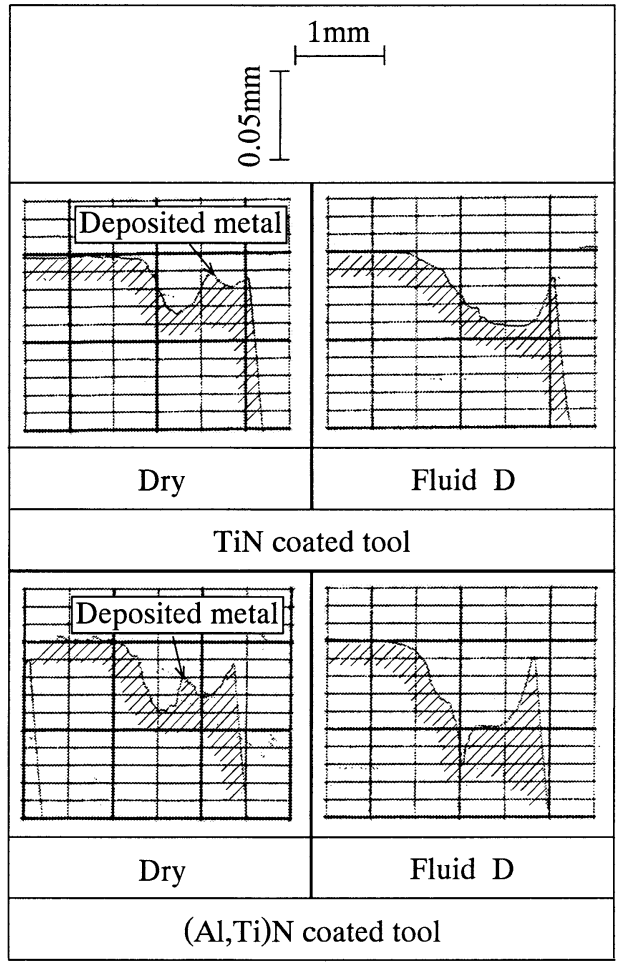

Fig. 14 Comparison of the profiles of crater wear (cutting speed of $117 \mathrm{~m} / \mathrm{min}$, cutting length of groove of $20 \mathrm{~m}$ )

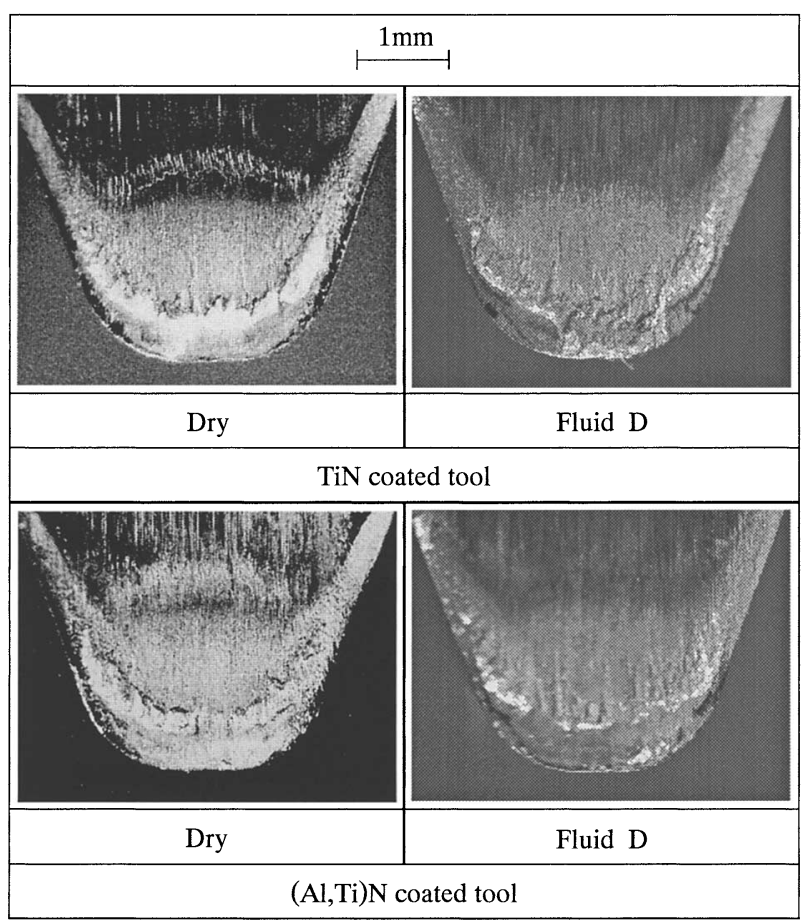

Fig. 15 Conditions of the rake face at the beginning of cut (cutting speed of $117 \mathrm{~m} / \mathrm{min}$, cutting length of groove of $0.5 \mathrm{~m}$ )

is prolonged, because the cutting edges are protected by the built-up edge ${ }^{(10)}$. Therefore, it is assumed that the adhesion of the deposited metal, just like the built-up edge,

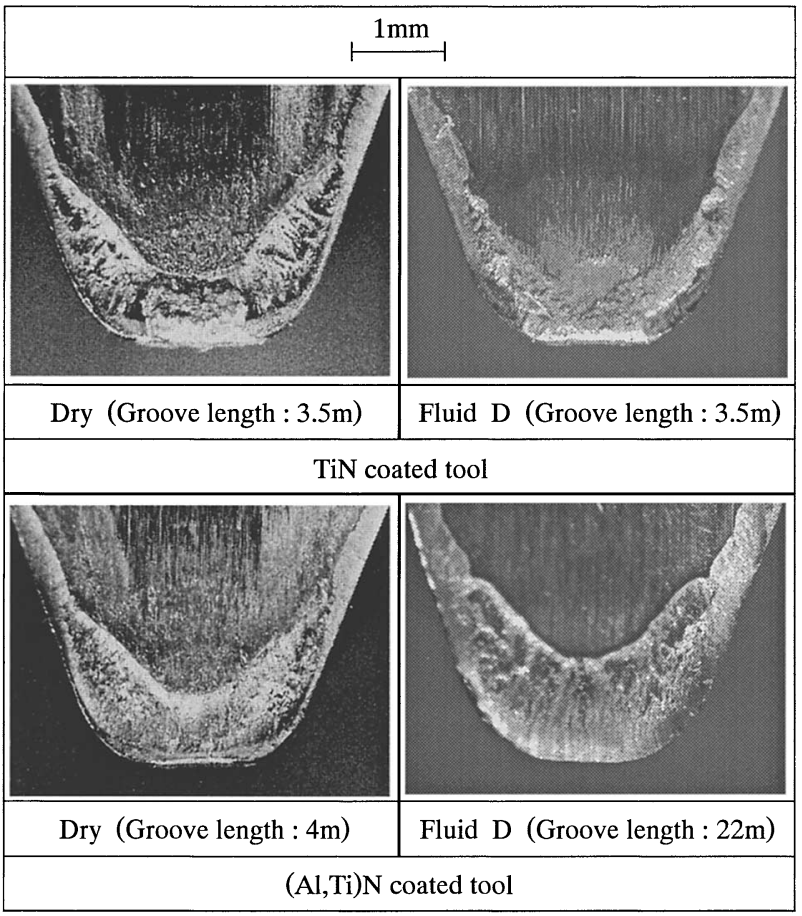

Fig. 16 Conditions of the rake face (cutting speed of $159 \mathrm{~m} / \mathrm{min}$ )

acts on the cutting edge effectively under this condition. Moreover, it can be said that the minute oxide compounds, such as $\mathrm{MnO}_{2}$ and $\mathrm{Al}_{2} \mathrm{O}_{3}$, form a protective layer (a belag) which obstructs the growth of wear caused by the diffusion on the tool surface during cutting, and which appears within a certain cutting speed range (the range of a certain cutting temperature $)^{(11)}$. Thus, the belag may be formed under this experimental condition, whose effect is also considered.

Figure 16 shows the conditions of the crater wear at the cutting speed of $159 \mathrm{~m} / \mathrm{min}$. In the case of the dry cutting and when using the Fluid D with TiN coated tool, the adhesion of the deposited metal is recognized on the crater area. However, it cannot be seen on the rake face of the $(\mathrm{Al}, \mathrm{Ti}) \mathrm{N}$ coated tool in the dry cutting and with the fluid. Therefore, the reason why the crater wear when using the fluids is smaller than that in the dry cutting at the high cutting speed of $159 \mathrm{~m} / \mathrm{min}$ is assumed that the rich cooling ability and the high absorbency of the fluids, as well as the additives such as sulfur and ester act to the crater wear effectively.

\subsection{Finished surface roughness $\mathrm{Ry}$}

Figure 17 shows the progress curves of finished surface roughness Ry obtained with the dry cutting and when using the fluids at the cutting speed of $117 \mathrm{~m} / \mathrm{min}$. When using the TiN coated tool, in the case of the dry cutting, the finished surface roughness value shows about $20 \mu \mathrm{m}$ at the beginning of cut, i.e., after cutting groove length of $0.5 \mathrm{~m}$. However, the surface roughness decreases rapidly 


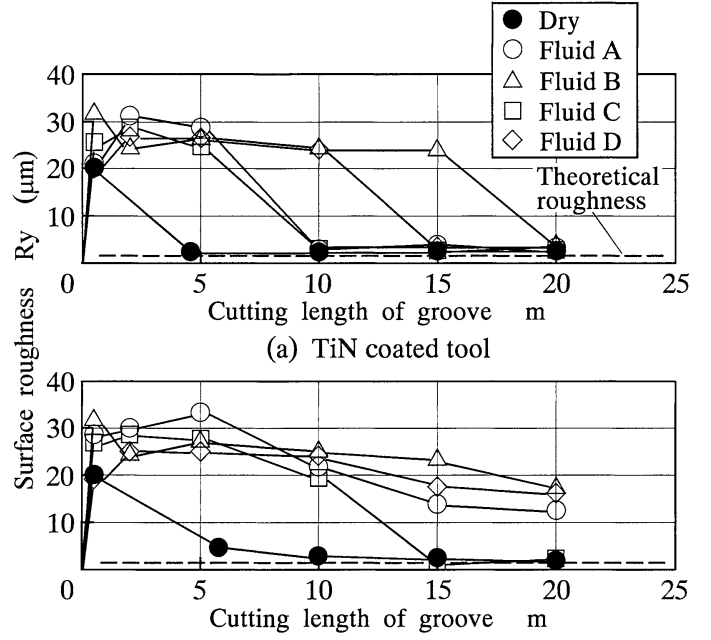

(b) $(\mathrm{Al}, \mathrm{Ti}) \mathrm{N}$ coated tool

Fig. 17 Progress curves of the surface roughness (cutting speed of $117 \mathrm{~m} / \mathrm{min}$ )

near cutting length of groove of $5 \mathrm{~m}$, whose value is approximately $2 \mu \mathrm{m}$ close to the theoretical roughness of $1.4 \mu \mathrm{m}$, and it is keeping almost the same value until the end of cutting of $20 \mathrm{~m}$ groove length. On the other hand, the surface roughness values obtained with the fluids are $25-30 \mu \mathrm{m}$ at the beginning of cut, which are larger than that obtained with the dry cutting, and after that, they have a tendency to decrease, but there is a cutting groove length, at which the surface roughness reduces rapidly, and it also differs according to the difference in the kinds of the fluids.

The surface roughness seems to be considerably related to the adhesion of the deposited metal on the cutting edge. Namely, it is big when the adhesion of deposited metal is recognized, whereas, it becomes small when the occurrence of deposited metal reduces, and the finished surface looks good even if the naked eyes can be seen. The reason why the occurrence of deposited metal decreases is assumed that when the crater wear width increases to some degree, the working rake angle becomes large, which smoothes the flowing of the cutting chips, resulting the decrease of deposited metal.

The surface roughness obtained with the $(\mathrm{Al}, \mathrm{Ti}) \mathrm{N}$ coated tool in the dry cutting also showed the same trend as in the case of TiN coated tool. Although the surface roughness values with the fluids are $25-35 \mu \mathrm{m}$ at the beginning of cut, after that, they show the tendency of decreasing. When using the fluids except for Fluid $\mathrm{C}$, the surface roughness showed $10-20 \mu \mathrm{m}$ at the end of cutting. In the case of Fluid $\mathrm{C}$, the surface roughness decreases rapidly after cutting a groove length of $15 \mathrm{~m}$, and after that, it showed the same value as the theoretical roughness.

Figure 18 illustrates the conditions and profiles of the finished surface after cutting groove lengths of $5 \mathrm{~m}$ and $10 \mathrm{~m}$ respectively, when using the Fluid $\mathrm{C}$, with TiN coated tool at the cutting speed of $117 \mathrm{~m} / \mathrm{min}$. In the case

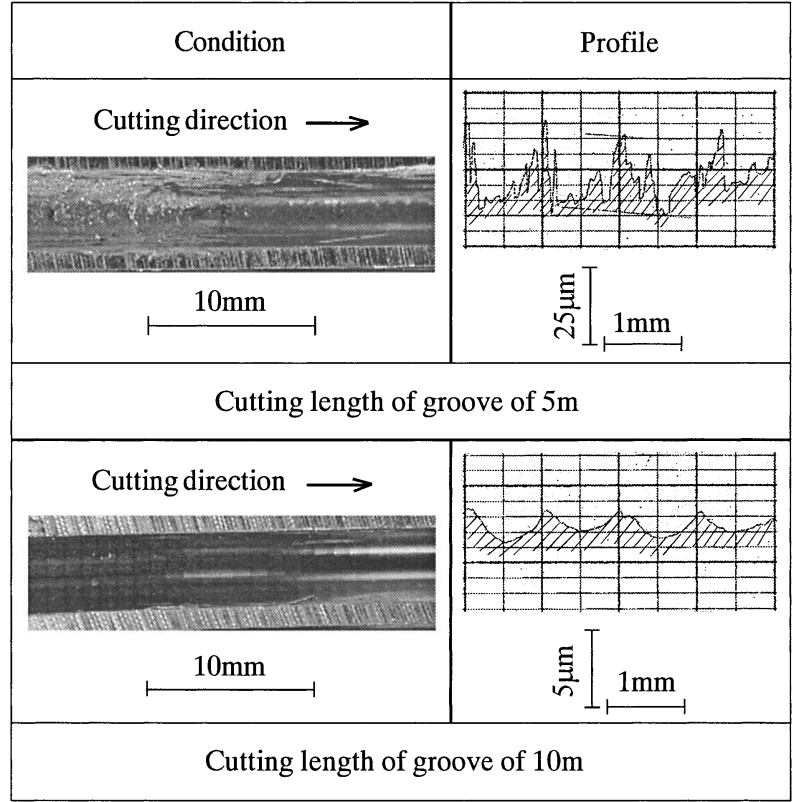

Fig. 18 Conditions and profiles of the finished surface (Fluid C, cutting speed of $117 \mathrm{~m} / \mathrm{min}$ )

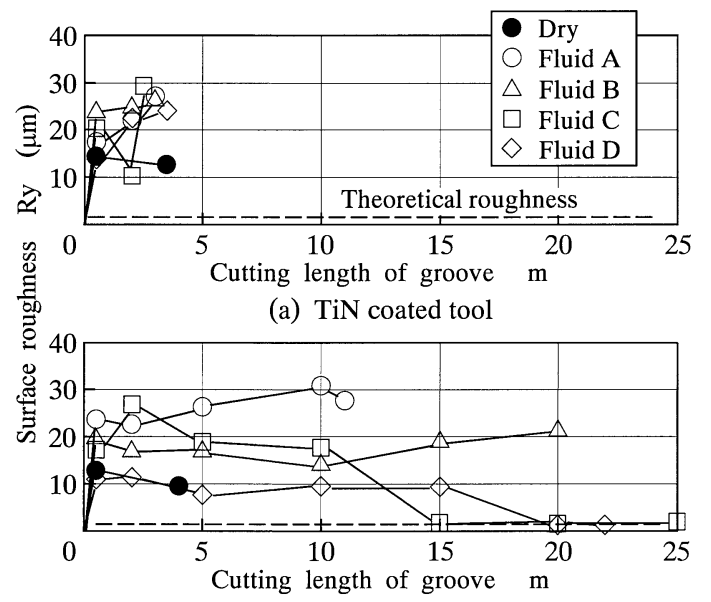

(b) $(\mathrm{Al}, \mathrm{Ti}) \mathrm{N}$ coated tool

Fig. 19 Progress curves of the surface roughness (cutting speed of $159 \mathrm{~m} / \mathrm{min}$ )

of the groove length of $5 \mathrm{~m}$, the machined surface has considerably been disturbed, and the cutter marks cannot be recognized either. When the groove length of $10 \mathrm{~m}$ was cut, though there are some disorders of the surface roughness, the cutter marks can be seen in the same interval as the feed rate $(0.99 \mathrm{~mm} / \mathrm{rev})$, and the stabilized beautiful surface was obtained.

The progress curves of surface roughness Ry obtained at the cutting speed of $159 \mathrm{~m} / \mathrm{min}$ are shown in Fig. 19. In the case of TiN coated tool, both in the dry cutting and when using the fluids, since the tests have been finished in the initial stage of cut, that is, as the maximum flank wear reached the tool life criterion, in which the occurrence of deposited metal increased, the surface roughness showed 
large values of $10-25 \mu \mathrm{m}$, and then they have a tendency to increase. However, the surface roughness decreases in the dry cutting. In the case of the $(\mathrm{Al}, \mathrm{Ti}) \mathrm{N}$ coated tool, the surface roughness obtained with the dry cutting is about $13 \mu \mathrm{m}$ at the beginning of cut, and after that, it decreases. With Fluids A and B, the surface roughness showed large values of $15-30 \mu \mathrm{m}$ until the end of cutting. On the contrary, with Fluids C and D, there exist the cutting groove lengths at which the surface roughness decrease rapidly, and after that, they show the same values as the theoretical roughness value until the end of cutting.

\section{Conclusions}

Fly tool cutting tests, to which the hobbing was simulated, were conducted using TiN and (Al,Ti)N coated tools made of high-speed steel with changing the cutting speed, in order to determine the cutting performances in the dry cutting and of the water-soluble cutting fluids, in terms of the flank wear (tool life), the crater wear and the finished surface roughness. As a consequence, the following points were clarified:

( 1 ) The flank wear obtained with the fluids using the TiN and $(\mathrm{Al}, \mathrm{Ti}) \mathrm{N}$ coated tools is larger than that obtained with the dry cutting at the cutting speed of $117 \mathrm{~m} / \mathrm{min}$. In the case of the TiN coated tool at the high cutting speed of $159 \mathrm{~m} / \mathrm{min}$, there is no difference in the tool life, which is very short, between in the dry cutting and when using the fluids, but with the $(\mathrm{Al}, \mathrm{Ti}) \mathrm{N}$ coated tool, it prolonged when using the fluids compared with the dry cutting.

(2) Though there are some fluids that show almost the same crater wear depth values as the dry cutting, with both the TiN and (Al,Ti)N coated tools at the cutting speed of $117 \mathrm{~m} / \mathrm{min}$, it is large when using the fluids on the whole. With the $(\mathrm{Al}, \mathrm{Ti}) \mathrm{N}$ coated tool at the cutting speed of $159 \mathrm{~m} / \mathrm{min}$, the crater wear obtained with fluids is smaller than that obtained with the dry cutting.

(3) The finished surface roughness when using the fluids is almost larger than that in the dry cutting, both with the TiN and (Al,Ti)N coated tools, irrespective of the change in the cutting speed. It was suggested that the surface roughness is closely connected with the occurrence of deposited metal.

(4) At the high cutting speed of $159 \mathrm{~m} / \mathrm{min}$, there are some fluids which have better cutting performance than that of the dry cutting, and in which the fluid containing the synthetic lubricating additive and the sulfuric EP additive is effective.

\section{Acknowledgements}

The authors wish to express their thanks to Mitsubishi Materials Kobe Tools Corporation for the supply of cutting tools.

\section{References}

( 1 ) Matsuoka, H., Ono, H. and Tsuda, Y., Fundamental Research on Water-Soluble Cutting Fluids for Hobbing (1st Report, Comparison of Performance with WaterInsoluble Cutting Oils), Trans. Jpn. Soc. Mech. Eng., (in Japanese), Vol.68, No.671, C (2002), pp.21882195.

( 2 ) Katsuki, A. and Matsuoka, H., Correspondence in Tool Wear between Hobbing and Cutting Using a Fly-Tool, Reports of the Faculty of Engineering Oita University, (in Japanese), No.23 (1991), pp.7-13.

( 3 ) Takeyama, H., Cutting, (in Japanese), (1982), pp.7678 , Maruzen.

( 4 ) Kimura, K. and Norose, S., Analysis and Countermeasure of Tribology, (in Japanese), (2003), pp.285-286, Technosystem.

( 5 ) Terashima, K. and Ueno, T., Numerical Analysis of Cutting Conditions of Space of Hob Tooth, Trans. Jpn. Soc. Mech. Eng., (in Japanese), Vol.43, No.373 (1977), pp.3535-3547.

( 6 ) Hiroi, S. and Nakayama, Y., Cutting and Grinding Fluids, (in Japanese), (1982), pp.44-47, Saiwaisyobou.

( 7 ) Hoffmeister, B., Der Verschleiß am Wälzfräser, Industrie-Anzeiger, 93.Jg.Nr.99 (1971), pp.2499-2504.

( 8 ) Hidaka, K., Ueno, T. and Terashima, K., Research on Wear of Hob Cutting Edge (On the Mechanism of Occurrence of Corner Wear), Trans. Jpn. Soc. Mech. Eng., (in Japanese), Vol.45, No.389 (1979), pp.129-135.

( 9 ) Kawai, H., Torii, N. and Sawa, Y., Analysis of Performance of Staggered Tooth Hob, Kougugihou, (in Japanese), No.22 (1974), pp.14-26, Kobe Steel.

(10) Hiroi, S. and Nakayama, Y., Cutting and Grinding Fluids, (in Japanese), (1982), pp.4-7, Saiwaisyobou.

(11) Aida, T., Koyama, M., Iwata, K., Okamura, K., Nakajima, T. and Hoshi, T., Cutting Technology, (in Japanese), (1973), pp.284-285, Corona Publishing Co., Ltd. 